\title{
Development of a Rapid and Sensitive Method for Detection of African Swine Fever Virus Using Loop-Mediated Isothermal Amplification
}

\author{
Xulong Wu ${ }^{1}$; Lu Xiao ${ }^{1, \dagger}$;Yin Wang ${ }^{1,2, *}$;Zexiao Yang ${ }^{1,2}$;Xueping Yao ${ }^{1,2}$;Bin Peng ${ }^{1}$. \\ ${ }^{1}$ College ofVeterinaryMedicine, SichuanAgriculturalUniversity, China; ${ }^{2}$ Key Laboratoryof Animal \\ DiseaseandHuman Health ofSichuanProvince, China; ${ }^{\dagger}$ Theseauthorscontributedequally.
}

\begin{abstract}
A loop-mediated isothermal amplification (LAMP) assay was developed for rapid, sensitive and specific detection of African swine fever virus (ASFV). A set of LAMP primers was designed based on the sequence of the ASFV gene $K 205 R$. Reaction temperature and time were optimized to $64{ }^{\circ} \mathrm{C}$ and $60 \mathrm{~min}$, respectively. LAMP products were detected by agarose gel electrophoresis or visually with the addition of fluorescent dye. The detection limit of the LAMP assay was approximately 6 copies of the target gene per microliter, 100 times more sensitive than conventional PCR. LAMP is a simple and inexpensive molecular assay format for ASFV detection. To date, African swine fever has not been reported in China. LAMP can be used to monitor ASFV spread into China, thereby reducing the threat of $A S F$.
\end{abstract}

Keywords: African swine fever virus; LAMP; K205R gene; molecular biology.

\footnotetext{
*Authors for correspondence: yaanwangyin@tom.com
} 


\section{INTRODUCTION}

African swine fever virus (ASFV) is an enveloped, complex, icosahedral virus with a double-stranded DNA genome of 170 to $190 \mathrm{~kb}$ in length (Takamatsu et al., 2013). It has been classified as the sole member of the new family Asfarviridae(Sanchez et al., 2013). This virus infects warthogs and bush pigs through bites from the argasid tick vector, as well as domesticated pigs and wild boar. It causes acute hemorrhagic fever and leads to high morbidity and mortality with consequent economic losses. There is no available vaccine for ASF (Karalyan et al., 2012).

Montgomery was the first to describe ASF, found in Kenya in 1921 (Gil et al., 2008). The virus spread from infected warthogs to domesticated pigs, causing disease with $100 \%$ mortality(Jezewska et al., 2011). In 1957, ASFV was reported in Lisbon, Portugal(Wieland et al., 2011). Following these reports, the disease was found on the Iberian Peninsula, and sporadic outbreaks occurred in France, Belgium and other European countries in the 1980s (Sampoli Benitez et al., 2013; Uttenthal et al., 2013). In the late 1970s, ASFV crossed the Atlantic Ocean and outbreaks were reported on some Caribbean islands, including Cuba and the Dominican Republic (de Glanville et al., 2014). The most recent outbreak of ASFV outside of Africa was in Georgia, at the beginning of 2007, and it has since spread to Azerbaijan and Russia, neighboring Armenia(Diaz et al., 2012; Uttenthal et al., 2013). So far, there have been no reports of ASF in China, but due to its geographical proximity, a plan of defense is urgently needed, making a rapid and sensitive detection method for ASFV of critical importance.

A variety of laboratory assays can be used to detect ASFV, including PCR (Howey et al., 2013) and real-time PCR (Oura, 2013), two assays that have been adopted for routine diagnosis. Although PCR is a highly sensitive method for the detection of ASFV, it relies on precision thermocycling which requires expensive instrumentation. Advances in molecular biology have seen the establishment of the loop-mediated isothermal amplification (LAMP) assay, originally described by Notomi et al (Notomi et al., 2000). LAMP allows rapid amplification of target DNA sequences in a highly specific manner under isothermal conditions. In this study, with the DNA polymerase Bst and specific internal and external primers enabled the identification of six independent regions of the target gene, we described the development of a rapid LAMP assay for the detection of ASFV, and compare this assay to PCR tests.

\section{MATERIALS AND METHODS}

\section{Preparation of DNA template and samples}

The $K 205 R$ gene of ASFV was synthesized by Invitrogen in Shanghai, China (GenBank accession no. NC_001659.1). The recombinant plasmid pMD18T-K205R was kept at $-70{ }^{\circ} \mathrm{C}$ until use as the template in ASFV LAMP and conventional PCR assays.

\section{Primer design}

LAMP primers were designed based on ASFV $K 205 R$. Two sets of primers recognized six different regions of the target gene-inner primers FIP and BIP, and outer primers F3 and B3. FIP consists of F1c, which is complementary to the F1 and F2 sequences. BIP consists of B1c, which is complementary to the B1 and F2 sequences (Fig. 1). A pair of specific PCR primers was also designed. The LAMP and PCR primer sequences are shown in Table 1.

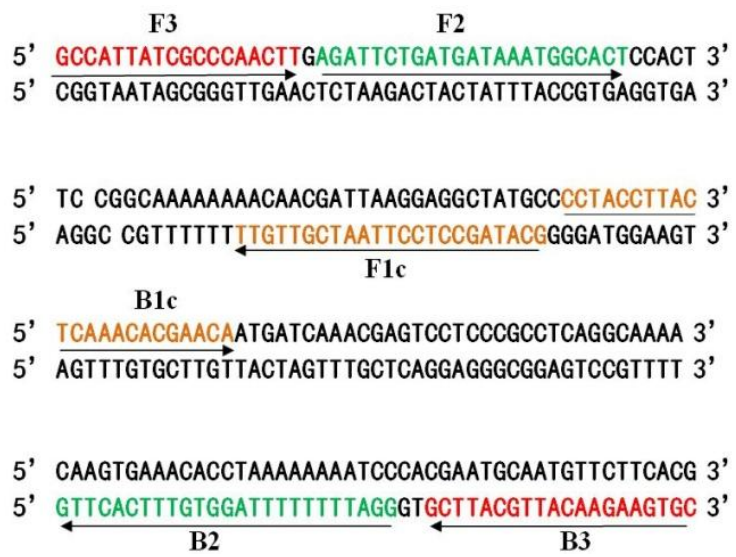

Figure 1: Location and sequences of ASFV K205R used to design the inner and outer primers. The sequences of the primer sites are underlined. 
Table 1: Oligonucleotide primer sets used for LAMP and conventional PCR

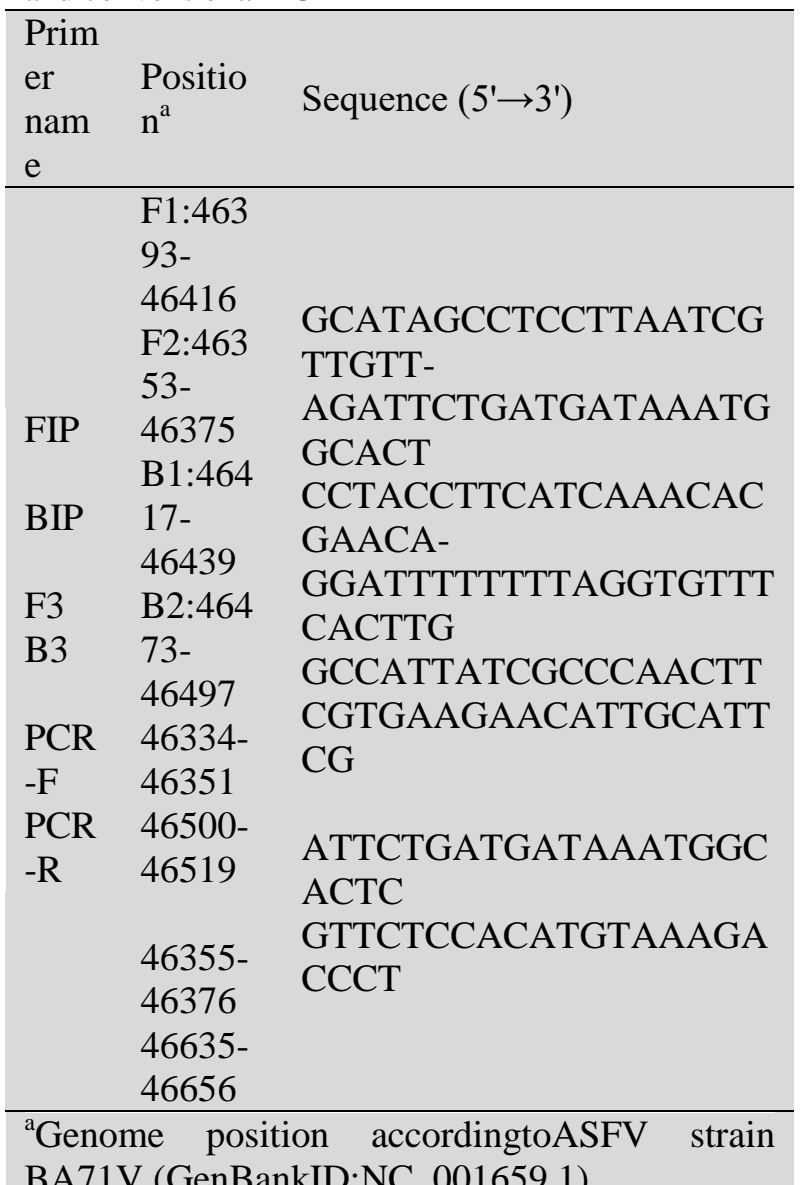

\section{Protocols for LAMP and PCR assays}

The LAMP assayreaction volume was $25 \mu$, consistingof $2.5 \mu \mathrm{l} \quad 10 \times \quad$ ThermoPolreaction buffer $(20 \mathrm{mM}$ Tris- $\mathrm{HCl}, 10 \mathrm{mMKCl}, 10 \mathrm{mM}$ $\left(\mathrm{NH}_{4}\right)_{2} \mathrm{SO}_{4}$, and $0.1 \%$ w/v Triton X-100; New EnglandBiolabs Inc.,Beverly, MA, USA), $8 \mathrm{U}$ of $B s t$ DNA polymerase (largefragment; New EnglandBiolabs), $0.2 \mu$ Mofeachouter primer and $2 \mu$ Mofeachinner primer, $1 \mathrm{M}$ betaine(SigmaAldrich, St. Louis, MO, USA), 0.6 mMdNTPs (2.5mMeach; TIANGEN Biotech), and4 $\mathrm{mM}$ $\mathrm{MgCl}_{2}$ (25mM; TIANGEN Biotech); $1 \mu \mathrm{ASFV}$ plasmidwasthenadded. The reactionwasrun in a gradientPCR

thermocycler(T100 ${ }^{\mathrm{TM}}$ ThermalCycler, Bio-Rad, Hercules, CA, USA). LAMP assayreactiontemperaturesof $60,61,62,63$, 64 and $65{ }^{\circ} \mathrm{C}$, andreaction times of $30,40,50$, and 60 minweretested. The amplificationproductswereanalyzedbyelectropho resison a $1.5 \%$ agarose gel for optimalreactionconditions.

The PCR wascarried out in a $25-\mu$ lreaction volume containing $0.2 \mu \mathrm{Meachofprimers} \mathrm{PCR-F}$ and PCR-R, $1 \mu \mathrm{l}$ DNA templateand $12.5 \mu 12 \times$ Taq PCR Mastermix(TIANGEN Biotech), consistingofTaq DNA enzyme,dNTPs, $\mathrm{MgCl}_{2}$, andthereaction buffer. The reactionswererun in a gradient PCR thermocycler $\left(\mathrm{T} 100^{\mathrm{TM}}\right.$ ThermalCycler) andtemperaturesof 56 , 57, 58, 59, 60 and $61{ }^{\circ}$ Cweretested. The amplificationproductswereanalyzedbyelectropho resison a $1.5 \%$ agarose gel to determine optimalconditions.

\section{Analysis of LAMP products}

In additiontoelectrophoreticanalysis, LAMP productswerealsodetectedvisually. LAMP productswereidentifiable as a largeamountofwhiteprecipitateformedduringthe LAMP reaction. In addition, 100-fold dilutedSYBR Green Istain (BioTekeBiotechCo., Ltd., Beijing, China) wasaddedtothereaction tube andthesolutionwasobserved for color changeunderultraviolet light. Green fluorescencewasobserved in positive reactions.

\section{Sensitivity of LAMP and PCR assays}

The ASFV plasmidsweresubjectedto serial 10fold dilutions, to a final concentrationof $6 \times 10^{0}$ to $6 \times 10^{4}$ copies $/ \mu 1$. The detectionlimitofthe LAMP assaywascomparedwiththatofthe PCR assayusingidenticalconcentrationsofthesame DNA templates. The optimizedmethodswereusedtodetectthesensitivit yof LAMP and PCR, with a reaction volume of $25 \mu 1$.

\section{RESULTS}

\section{Optimization of reaction conditions}

The LAMP productsappearedontheagarose gel in a ladder-likepatternatdifferenttemperatures $\left(60,61,62,63,64\right.$ and $\left.65{ }^{\circ} \mathrm{C}\right)$ anddifferent times $(30, \quad 40, \quad 50, \quad$ and $60 \quad \mathrm{~min})$. Little differencewasfound in theelectrophoreticpatternsat 60 and $65^{\circ} \mathrm{C}$ (Fig. 2a),

andtheamountofamplificationproductwaslargesta fter 60 min reaction (Fig. 2b). Thus, $64{ }^{\circ} \mathrm{C}$ for 60 min wasselected as theoptimalreactioncondition for ASFV LAMP assay, andthecomponentsandaddedvolumes for the LAMP reaction are given in Table 2. Agarose gel electrophoresis of the ASFV PCR products indicated $\quad 59 \quad{ }^{\circ} \mathrm{C} \quad$ as theoptimalreactiontemperature for thisassay (Fig. 2c). 

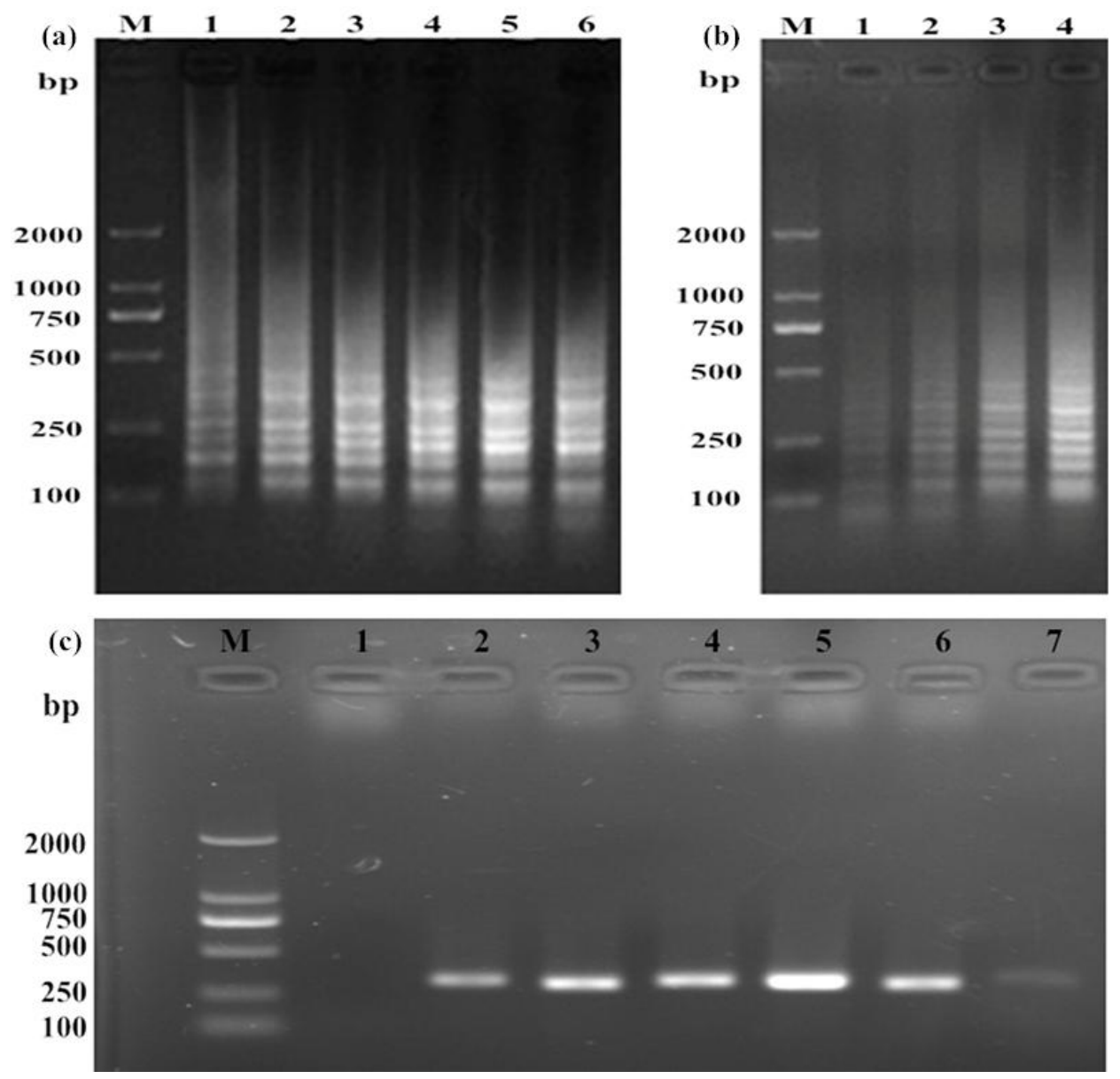

Figure 2:Optimizationof LAMP and PCR for ASFV detection. The LAMP reactionwasrununderdifferenttemperaturesand times, andtheproductswereexaminedbyagarose gel electrophoresis. (a)Lanes 1-6: LAMP wascarried out at 60, 61, 62, 63, 64 and $65^{\circ} \mathrm{C}$, respectively. (b) Lanes 1-4: LAMP wascarried out for 30, 40, 50 and $60 \mathrm{~min}$, respectively. (c) Lane 1: negative control; lanes 2-7: PCR wascarried out at 56, 57, 58, 59, 60 and $61^{\circ} \mathrm{C}$, respectively. Lane M: DNA Marker (DL 2000).

Table 2: LAMP reaction conditions

\begin{tabular}{ll}
\hline Components & Volume $(\mu \mathrm{l})$ \\
\hline Bst DNA polymerase $(8 \mathrm{U})$ & 1 \\
ThermoPol buffer $(10 \times)$ & 2.5 \\
dNTPs $(2.5 \mathrm{mM}$ each $)$ & 6 \\
$\mathrm{MgCl}_{2}(25 \mathrm{mM})$ & 4 \\
Betaine $(1 \mathrm{M})$ & 2.5 \\
Outer primers $(5 \mu \mathrm{M}$ each $)$ & 1 \\
Inner primers $(50 \mu \mathrm{M}$ each $)$ & 1 \\
Template & 1 \\
Deionized water & 4 \\
Total & 25 \\
\hline
\end{tabular}

\section{Visual detection of ASF V LAMP}

As alreadynoted, agarose gel electrophoresisofthe LAMP productsshown a ladder-likepatternwithfragmentsofdifferentsizes (Fig. 3a). In addition, the ASFV LAMP productswerevisuallydetectedbytheirturbidity in thereaction tubes. In ASFV-positive samples, turbiditycouldbeseenwiththenakedeyeunder natural light (Fig. 3b), whereastherewas no turbiditywiththe negative samples. Uponadditionof $1 \mu \mathrm{l}$ SYBR Green I (100-fold dilution), greenfluorescencecouldbeobserved in the positive tubes underultraviolet light, and no fluorescencewasseen in the negative ones (Fig. $3 c)$. 


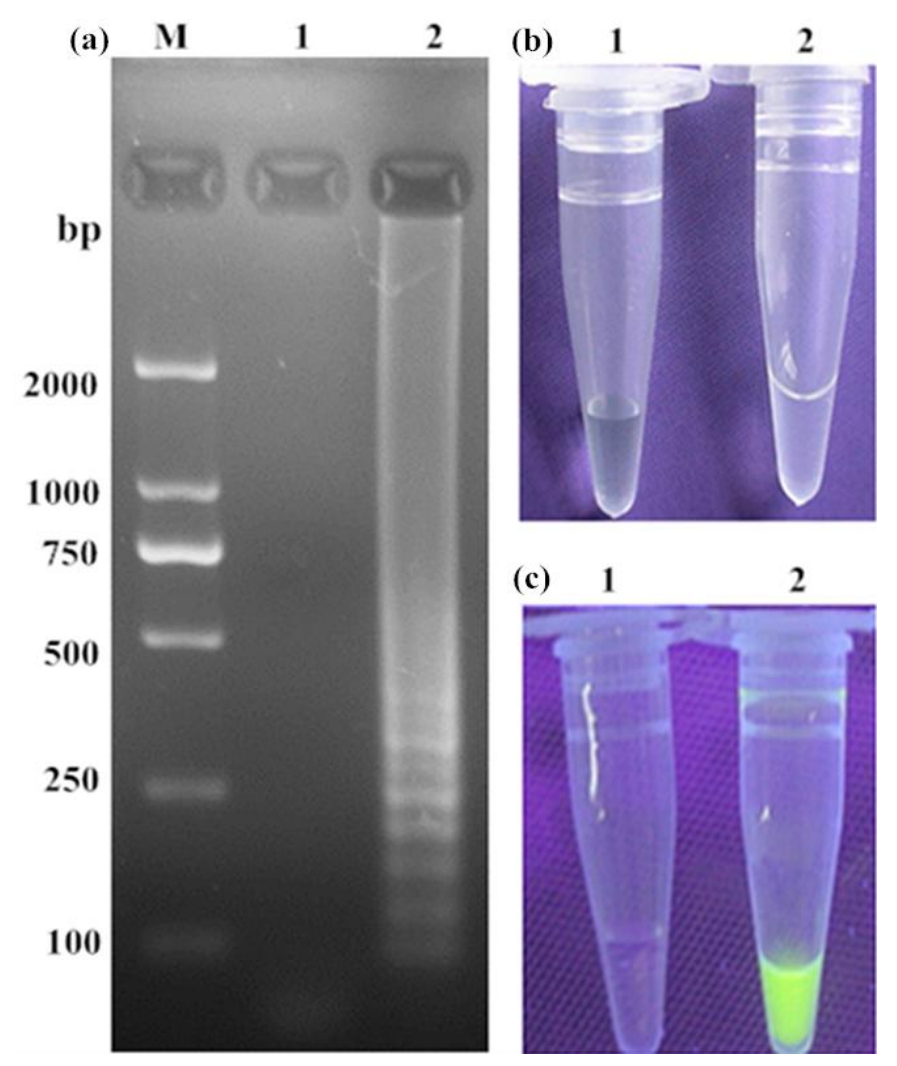

Figure 3:Analysisof LAMP products. (a) LAMP productsdetectedbyelectrophoreticanalysis. (b) Visual observationunder natural light. (c) Visual observationfollowingtheadditionof SYBR Green I underultraviolet light.Lane M: DNA marker (DL 2000); 1: negative controlreaction; 2: positive reaction.

\section{Detection limits of LAMP and conventional} PCR

LAMP andconventional PCR werecarried out andtheirrespectivedetectionlimitscomparedusing 10 -fold serial dilutions $\left(6 \times 10^{0}\right.$ to $6 \times 10^{4}$ copies/ $\mu$ l) of ASFV recombinantplasmid as thetemplate. Wecoulddetect 6 copies/ $\mu$ DNA by LAMP (Fig. 4a), whereastheminimumdetectableamount for PCR was $6 \times 10^{2}$ copies/ $\mu$ l (Fig. 4 b). Thus, the LAMP assaywasapproximately 100

times moresensitivethanthe PCR assay.
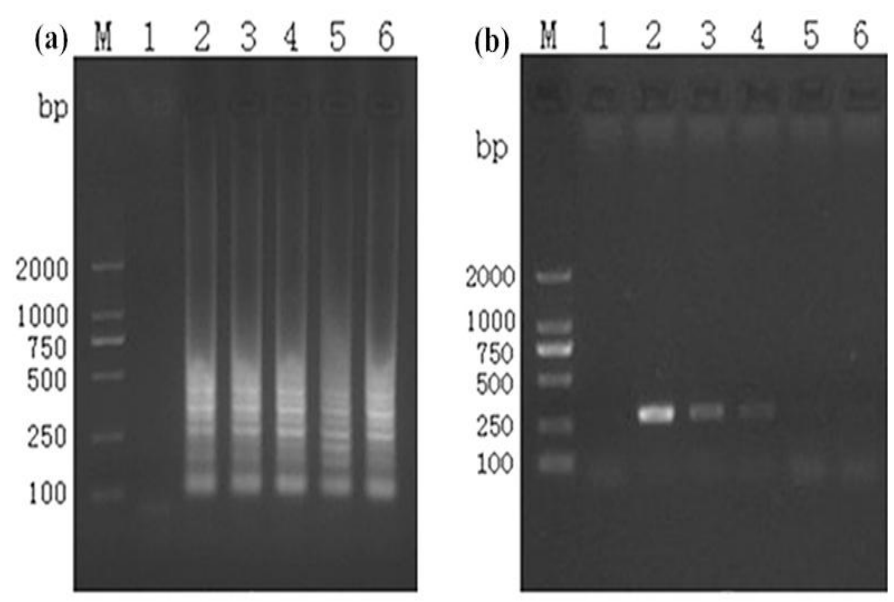

Figure 4:Sensitivitiesof LAMP (a) and PCR (b) assays for ASFV detection, using 10-fold serial dilutionsofthesametemplate. Lane M: DNA Marker (DL 2000); lane 1: negative controlreaction; lanes 2-6: $6 \times 10^{4}, 6 \times 10^{3}, 6 \times 10^{2}, 6 \times 10^{1}$, and $6 \times 10^{0}$ copies $/ \mu 1$, respectively. 


\section{DISCUSSION}

To date, therehasbeen no recordedoccurrenceof ASF in China, but in thecontextofglobalization, withthedevelopmentofimport,export trade andfrequentmovementofpersonnel, ASFV wouldbea threat for China, dealing a devastatingblowtopig-breedingindustryof China. Thereis no efficienttreatmentmeasureorvaccine for thecontrolof

ASFnow, themaincontrolmeasureremainsquarantin e. A simple, rapid, andsensitiveassay for thedetectionof ASFV isessential.In thisstudy, a novel

LAMP

diagnosticprotocolwasestablishedtodetectthisvirus. Therehasbeen quite a bit ofresearchonP72, P73andP54 of ASFV. However, there are fewstudieson ASFV K205R. K205Ris a conservedandspecific ASFV gene thatappears in earlyinfectionandismostrapidlyamplified(Cobbold et al., 2001; Gutierrez-Castaneda et al., 2008). In addition, PK205R canbeexpressedwhen ASFV just invades. Thesemake it a powerfulindicator for thedetectionof ASFV. In ourstudy, thetarget gene wasamplifiedwellonly in $60 \mathrm{~min}$,but it needsatleast 2-3 h for conventional PCR.

LAMP wasverysensitive for ASFV detection, approximately 100-fold more sensitivethanconventional PCR usedwiththesame DNA template. The minimumdetectableamountof LAMP was $6 \quad$ copies $/ \mu 1$, andthusthisassaycandetectthevirus in earlyasymptomaticinfectedsamples. The high sensitivityof LAMP can serve for diseasesurveillance, andmakes it suitable for use in theChineseEntry-ExitInspectionandQuarantine Bureau toprevent ASFV spread into China. In addition, LAMP productsappear as whiteprecipitatestothenakedeye, as explainedby Mori et al. (Mori et al., 2001). Visual detectionofLAMP

productscanalsobeperformedusing

a

fluorescentchromogenwithnucleicacidstain(Cardos o et al., 2010; Suebsing et al., 2013). Therefore, thenovel LAMP assay for ASFV describedhereinis more practical for routine ASFV detectionthanconventional PCR.

In conclusion, a rapid and sensitive LAMP assay for the detection of ASFV was developed and validated. The LAMP reaction took approximately $1 \mathrm{~h}$ in a PCR thermocycler, or in a water bath at 64 ${ }^{\circ} \mathrm{C}$. The detection limit of the ASFV LAMP assay was as low as 6 copies per $\mu$ DNA, 100 times more sensitive than that of conventional PCR. LAMP products could be detected by agarose gel electrophoresis, but also visually. The LAMP assay is a rapid, simple, specific, sensitive and reliable diagnostic protocol that can be applied under field conditions, even at China's trade borders, to prevent ASFV spread into China. This technique for ASFV detection holds great potential, pending further refinement.

\section{ACKNOWLEDGMENT}

We gratefully acknowledge financial support for this work from the planning subject of 'the twelfth five-year-plan' in national science and technology for rural development in China (2013BAD12B04).

\section{REFERENCES}

1. Cardoso TC, Ferrari HF, Bregano LC, Silva-Frade C, Rosa AC, Andrade AL. Visual detection of turkey coronavirus RNA in tissues and feces by reverse-transcription loop-mediated isothermal amplification (RT-LAMP) with hydroxynaphthol blue dye. Molecular and cellular probes 2010; 24: 415-417.

2. Cobbold C, Windsor M, Wileman T. A virally encoded chaperone specialized for folding of the major capsid protein of African swine fever virus. Journal of virology 2001; 75: 7221-7229.

3. de Glanville WA, Vial L, Costard S, Wieland B, Pfeiffer DU. Spatial multi-criteria decision analysis to predict suitability for African swine fever endemicity in Africa. BMC veterinary research 2014; 10: 9 .

4. Diaz AV, Netherton CL, Dixon LK, Wilson AJ. African swine fever virus strain Georgia 2007/1 in Ornithodoros erraticus ticks. Emerging infectious diseases 2012; 18: 1026-1028.

5. Gil S, Sepulveda N, Albina E, Leitao A, Martins C. The low-virulent African swine fever virus (ASFV/NH/P68) induces enhanced expression and production of relevant regulatory cytokines (IFNalpha, TNFalpha and IL12p40) on porcine macrophages in comparison to the highly virulent ASFV/L60. Archives of virology 2008; 153: 18451854.

6. Gutierrez-Castaneda B, Reis AL, Corteyn A, Parkhouse RM, Kollnberger S. Expression, cellular localization and antibody responses of the African swine fever virus genes B602L and K205R. Archives of virology 2008; 153: 2303-2306. 
7. Howey EB, O'Donnell V, de Carvalho Ferreira HC, Borca MV, Arzt J. Pathogenesis of highly virulent African swine fever virus in domestic pigs exposed via intraoropharyngeal, intranasopharyngeal, and intramuscular inoculation, and by direct contact with infected pigs. Virus research 2013; 178: 328339.

8. Jezewska MJ, Szymanski MR, Bujalowski W. Interactions of the DNA polymerase $\mathrm{X}$ from African Swine Fever Virus with the ssDNA. Properties of the total DNA-binding site and the strong DNAbinding subsite. Biophysical chemistry 2011; 158 : 26-37.

9. Karalyan Z, Zakaryan H, Arzumanyan H, Sargsyan K, Voskanyan H, Hakobyan L, Abroyan L, Avetisyan A, Karalova E. Pathology of porcine peripheral white blood cells during infection with African swine fever virus. BMC veterinary research 2012; 8: 18.

10. Mori Y, Nagamine K, Tomita N, Notomi T. Detection of loop-mediated isothermal amplification reaction by turbidity derived from magnesium pyrophosphate formation. Biochemical and biophysical research communications 2001; 289: $150-154$

11. Notomi T, Okayama H, Masubuchi H, Yonekawa T, Watanabe K, Amino N, Hase T. Loop-mediated isothermal amplification of DNA. Nucleic acids research 2000; 28: E63.

12. Oura C. African swine fever virus: on the move and dangerous. The Veterinary record 2013; 173: 243 245.

13. Sampoli Benitez B, Barbati ZR, Arora K, Bogdanovic J, Schlick T. How DNA polymerase X preferentially accommodates incoming dATP opposite 8-oxoguanine on the template. Biophysical journal 2013; 105: 2559-2568.
14. Sanchez EG, Quintas A, Nogal M, Castello A, Revilla Y. African swine fever virus controls the host transcription and cellular machinery of protein synthesis. Virus research 2013; 173: 58-75.

15. Suebsing R, Prombun P, Kiatpathomchai W. Reverse transcription loop-mediated isothermal amplification (RT-LAMP) combined with colorimetric gold nanoparticle (AuNP) probe assay for visual detection of Penaeus vannamei nodavirus (PvNV). Letters in applied microbiology 2013; 56: 428-435.

16. Takamatsu HH, Denyer MS, Lacasta A, Stirling CM, Argilaguet JM, Netherton CL, Oura CA, Martins C, Rodriguez F. Cellular immunity in ASFV responses. Virus research 2013; 173: 110121.

17. Uttenthal A, Braae UC, Ngowi HA, Rasmussen TB, Nielsen J, Johansen MV. ASFV in Tanzania: asymptomatic pigs harbor virus of molecular similarity to Georgia 2007. Veterinary microbiology 2013; 165: 173-176.

18. Wieland B, Dhollander S, Salman M, Koenen F. Qualitative risk assessment in a data-scarce environment: a model to assess the impact of control measures on spread of African Swine Fever. Preventive veterinary medicine 2011;99: 4-14. 